\title{
A Study on Persuasive Language in Personal Selling
}

\author{
Danyan Huang ${ }^{1}$ \\ ${ }^{1}$ International College, Guangdong University of Foreign Studies, Guangzhou, China \\ Correspondence: Danyan Huang, International College, Guangdong University of Foreign Studies, Guangzhou, \\ 510420, China. E-mail: 201020017@oamail.gdufs.edu.cn
}

$\begin{array}{ll}\text { Received: December 29, } 2018 & \text { Accepted: February 2, } 2019 \quad \text { Online Published: March 2, } 2019 \\ \text { doi:10.5539/ijel.v9n2p353 } & \text { URL: https://doi.org/10.5539/ijel.v9n2p353 }\end{array}$

\begin{abstract}
The present study, which is qualitative in nature, is an investigation into the persuasive language used in the interactive communication of personal selling based on Jef Verschueren's linguistic Adaptation Theory and some important ideas of Game Theory. Within the framework of these theories, four personal selling cases were analyzed to reveal the interactive process of selling between the seller and the buyer as if they were engaged in a game in which the former used various persuasion strategies in different stages of selling to adapt to the physical, social and mental world of the latter. The two successful cases revealed that the seller's sound adaptation to the three worlds of the buyer ultimately helped him/her to achieve a win-win situation while the two unsuccessful ones showed that the failure to adapt to any one of the three worlds led to a failed selling attempt and unproductive interaction between the two parties.
\end{abstract}

Keywords: game theory, linguistic adaptation theory, personal selling

\section{Introduction}

Selling is a driving force for the global economy and a vital part of virtually every human interaction. Countries depend upon the sales process to survive. Companies exist for the sole purpose of meeting the needs of their customers through products or services. Without sales they go bankrupt.

"Personal selling is a person-to-person business activity in which a salesperson uncovers and satisfies the needs of a buyer to the mutual, long-term benefit of both parties" (Barton, Stephen, \& John, 2004, p. 4). This definition stresses that selling is more than making a sale and getting an order. The objective is to build a relationship - a partnership - that provides long-term benefits to both the seller and the customer. Thus selling involves helping customers identify problems, offering information about potential solutions, and providing after-the-sale service to ensure long-term satisfaction.

As for the process of personal selling, Rolph (1995) presented a useful seven-stage model: prospecting and qualifying, planning the sales call, approaching the prospect, making the sales presentation, negotiating resistance or objections, confirming and closing the sale, and servicing the account. These seven stages of personal selling are equally important for the salesperson to convince the potential customer to purchase his/her product or service. However, the present study focuses only on these four stages: approaching the prospect, making the sales presentation, negotiating resistance or objections, and confirming and closing the sale, since our aim is to analyze the persuasion language and strategies used in the face-to-face interaction between the salesperson and the customer.

\section{Literature Review}

\subsection{Persuasion}

Humans have studied persuasion for centuries and have offered many definitions for the word. The formal study of persuasion traces its roots to ancient Greeks, who were the first to systematize the use of persuasion, calling it "rhetoric". Among these ancient theorists was Aristotle, who defined rhetoric, a term used interchangeably with persuasion, as "the faculty of observing in any given case, the available means of persuasion" (1991, p. 36). Timothy defined persuasion as "the coproduction of meaning that results when an individual or a group of individuals uses language strategies and/or visual images to make audiences identify with that individual or group" (2002, p. 15). Charles treated persuasion as "a process of co-creating a state of identification between a source and a receiver that results from the use of verbal and/or visual symbols" (2004, p. 11). 
The present study mainly deals with the realization of persuasion in personal selling, a context involving two parties, the salesperson and the prospecting customer, who seem to be in conflict when interests are concerned. The salesperson, in an attempt to gain his/her interests, tries to persuade the other party to purchase his/her good or service, while the targeted customer attempts to defend his/her own interests by posing various objections, such as the unacceptability of the price of the good or service recommended. Thus, in order to successfully persuade the customer to purchase, the salesperson, as a persuader, should adopt effective persuasive strategies by adapting to the particular needs of the targeted customer, that is, for a start the salesperson needs to know about his/her customer, and by prioritizing the customer's interests, to design customized approaching, attention-attracting and needs-satisfying strategies.

From the works of such experts as Weymes (1990), Hafer (1993) and Sun (2007), some persuasion strategies can be summarized, which are in line with the Greek's classification of artistic proofs appeals: ehos (relating to the credibility of the persuader), pathos (relating to the emotions and involving appeals to the passions or the will of the audience) and logos (referring to appeals to the intellect or to the rational side of humans) (1991) and Walter's model of persuasion in which "stories" take on the role of convincing arguments (1987). For each stage the choice of persuasion tactics or techniques is different and unique. For the approaching stage, there are several common techniques: news approach, referral approach, bonus approach, customer benefit approach, curiosity approach, shock approach, service approach, to name a few. As to the presentation stage, such techniques are among the most widely used: telling a stimulating sales story, emphasizing unique selling points, creating a relaxed selling atmosphere, using good third-party testimonials, and using sales literature and visual aids. As for the negotiating stage, some popular objections handling tactics have been developed, such as the forestalling method, the digging technique, the defer technique, the boomerang method, the indirect denial and the superior point technique. For the closing stage, the widely accepted techniques are: the suggestion close, the assumption close, the alternative close, the isolation technique, the active close, the concession sale, the balance-sheet close, part-by-part technique, the urgency or impending event close, narrative close and the 'if' technique, etc. Some, if not all these tactics or techniques will be mentioned when some on-spot cases are discussed. The point which has to be emphasized here is that the choice of strategies in personal selling varies according to the different stages and the different products to be sold as well.

\subsection{Verschueren's Linguistic Adaptation Theory}

In his book titled Understanding Pragmatics, Verschueren (1999) presented a new pragmatic approach to investigate and explain the meaningful functioning of language cognitively mediated and performed in social and cultural contexts. To answer the general question of what people do when using language, he argued that "using language must consist of the continuous making of linguistic choices, consciously or unconsciously, for language-internal (i.e., structural) and/or language-external reasons" (p. 55). As to the extent the choices are made, the choices can be situated "at any level of linguistic form: phonetic/phonological, morphological, syntactic, lexical, and semantic, and they may range over variety-internal options, or they may involve regionally, socially or functionally distributed types of variation" (p. 56).

To make sense of the notion of "making choices", Verschueren advanced three features of language: variability, negotiability and adaptability, which enable the choice-making to go on smoothly in the course of interaction. Variability is the property of language "which defines the range of possibilities from which choices can be made" (Verschueren, 1999, p. 59). Variability allows the language user to be able to make choices at all levels of language structure. "Negotiability is the property of language responsible for the fact that choices are not made mechanically or according to strict rules or fixed form-function relationships, but rather on the basis of highly flexible principles and strategies" (Verschueren, 1999, p. 60). In other words, in expressing himself/herself, the language user chooses strategies, which have to do with purposes. Whatever linguistic choice one makes, there should be a certain reason behind it. "Adaptability, then is the property of language which enables human beings to make negotiable linguistic choices from a variable range of possibilities in such a way as to approach points of satisfaction for communicative needs" (Verschueren, 1999, pp. 61-62).

Using adaptability as the starting point, Verschueren (1999) described and explained the use of language from four angles: contextual correlates of adaptability, structural objects of adaptability, dynamics of adaptability, and salience of the adaptation process. According to him, contextual correlates of adaptability potentially include all the ingredients of the communicative context with which linguistic choices have to be inter-adaptable, and the range goes from aspects of the physical surroundings to social relationships between language producers and language interpreters and aspects of the language users' (producers \& interpreters) state of mind. To be specific, all the ingredients that are inter-adaptable include: language users (utterer and interpreter), mental world (such as personality, emotions, beliefs, desires or wishers, motivations or intentions, etc. of language users), social world 
(such as social settings, institutions, culture, etc.) and physical world (such as time, space, bodily postures, physical appearance, physical conditions, biological property, etc.

\subsection{Game Theory}

Game Theory, initially a mathematical theory, is developed by John and Oskar (2004). Their work Theory of Games and Economic Behavior in which they first formalized the subject in 1944 is now assumed classic. Game Theory, as a branch of mathematics and a modern approach to interest conflicts, uses models to study interactions with formalized incentive structures (games). Since the late 1970s Game Theory has been a useful tool in analyzing situations in which the rational decision-making depends on mutual expectations about the action of the other(s). The primary concern of Game Theory can be viewed as the problem of individuals reaching decisions when they are in conflict with other individuals and when there is a risk involved in the outcomes of their choices. Therefore, it is a theory of rational behavior for interactive decision problems.

Some basic concepts and techniques of Game Theory have been widely adopted. It has provided a means for analyzing many problems of interest, and much of the fundamental work has been done by researchers in such fields, like economists, management science, collective action, political science, psychology and biology. In addition, its theoretic analysis can be applied in simple games of entertainment, such as card games, chess and soccer, or to more significant aspects of life and society.

The concepts of Game Theory have been used to sharpen the informal idea of language games in a theory of natural language semantics developed by Jaakko Hintikka and his associates in the 1970s. To be specific, the theory is a version of model-theoretic semantics, known as Hintikka's game theoretical semantics (2006), in which the key concept is that of the truth of a sentence in a possible world or model. The primary idea is that the truth of each sentence $S$ is defined by reference to an associated semantic game $G(S)$. In a sense, $G(S)$ may be considered as an attempt to verify $\mathrm{S}$, the sentences chosen are progressively reduced in complexity until an atomic sentence results after a finite number of moves, and further move is impossible. Influenced by Hintikka's game theoretical semantics and his theory of information-seeking dialogues in philosophy, Carlson developed a dialogue game framework to approach coherence in question-answer dialogues (Carlson, 1983).

According to Carlson, "no one will deny that studying the nature of the rules of games must be useful for the study of grammatical rules, since it is beyond doubt there is some sort of similarity between them" (Carlson, 1983, p. 104), Carlson assumed that language games were what established the link between language to the reality described and transformed by it. He pointed out that language and actions denoted by it constituted a language game. He emphasized the goal-directed character of language use, and stressed the significance of understanding the internal aim or rule of winning so as to master language game. To justify the feasibility of his tentative theory of language games, he sought a precise definition of a game (of strategy) in the mathematical theory of games. As a matter of fact, Carlson developed a fairly abstract unified theoretical framework for discourse analysis, namely the dialogue game approach, and claimed that "a discourse is coherent if it can be extended into a well-formed dialogue game" (Carlson, 1983, p. 104). His dialogue games are "cooperative activities of information exchange: the players strive to achieve a common understanding on the basis of observation and considered opinion" (Carlson, 1983, p. 108).

Morton (2017), based on the number of players involved in a game and the extent to which their interests coincide or conflict, divided games into three types: the two-person, zero-sum game, the two-person, non-zero-sum game and the n-person game. The term "two person" can both refer to two individuals and two groups of people as the two parties in a game, while "n-person" means that more than two parties are involved in a game. The term "zero-sum" means that the players have diametrically opposed interests, and that if one party wants to win, others have to lose, while "non-zero-sum" means that both parties may simultaneously gain, in other words, a win-win situation can be achieved in a game. According to him, in a two-person game, there are generally both competitive and cooperative elements: the interests of the players are opposed in some respects and complementary in others. And he regarded all two-person games as lying in a continuum, with the zero-sum games at one extreme since the players have no common interests, the completely cooperative game at the other extreme since the players have nothing but common interests, and the rest of the two-person games in between.

Personal selling can be treated as a two-person non-zero-sum game in that two parties: the salesperson and the customer are involved, and that they can both win by getting what they want through bargaining or negotiation. However, to achieve a win-win situation, or bilateral optimalization between both parties in personal selling, the choice of persuasion strategies and cooperation between them is essential, since both tend to adopt strategies to adapt to the dynamically moving process of communication in order to maximize their final benefits (i.e., each individual strives to maximize his utility in terms of Game Theory). 


\section{Method}

\subsection{Research Questions}

The basic purpose of this research is to study persuasion in personal selling language based on Linguistic Adaptation Theory and Game Theory.

In view with the purpose described above, the following questions are to be answered through the study:

1) What effective persuasive strategies in language have usually been chosen by salespeople in each stage of personal selling?

2) How those contextual factors proposed by Jef Verschuren influence the choice of persuasive strategies by salespeople?

3) How persuasion helps to achieve bi-directional optimalization in the specific interpersonal communication of personal selling?

\subsection{Research Methodology of the Present Study}

The present research is a qualitative research in the sense that it aims to do research on the data "that occur naturally, without the intervention of an experiment or artificially contrived treatment" (Seliger, 1989, p. 116). Qualitative research is more suitable than quantitative one for the present study for several reasons. First of all, the topic of the investigation is about persuasive language in personal selling, that is, the subjective experience of the participants in the communication. The purpose of investigating the communication is, then, to make sense of a subjective experience. A qualitative approach is one way in which such understanding is interpreted. Secondly, the Linguistic Adaptation Theory itself is "interpretive" method, and it is applied to analyze the dynamic processes of language use by humans, or to understand the functioning of language in its full complexity. Thirdly, the data collected are not from probability sampling, so they cannot be used to make an absolute conclusion about all the persuasion (in terms of both word choice and strategy adoption) in personal selling. Lastly, the present research is mainly to answer "how" questions about persuasion in personal selling and is not intended to grab the features of something in terms of scale and level.

\subsection{Data Collection and Analysis}

The target data for analysis in this study are mainly conversations in English, which are collected from some books concerning selling. The cases used here are on-spot conversations or talks videotaped and transcribed by the authors while they are conducting researches to finish the writing of their books which are meant to serve as textbooks for students to learn the art of selling, and thus the authenticity of the data can be guaranteed.

The data collected are categorized and analyzed according to the above mentioned theoretical framework to discover what kinds of persuasion language strategies have been used in different stages of personal selling, how the salesperson adapt to the physical, social and mental world, and whether and how a win-win situation is achieved between the two parties involved in the selling game. Also a comparison will be conducted between successful cases and failed ones, therefore displaying the importance of adopting persuasive language and strategies in selling. In this way, the answers to the research questions will be finally induced and presented through the analysis of these personal selling conversations.

\section{Case Analysis}

In this section, four complete cases of personal selling, two being successful and two being failed, will be firstly presented and then analyzed based on the two main theories outlined above. An integrated approach is adopted in that firstly all the four cases reveal the whole process of face-to-face interaction between the salesperson and the prospect or customer in typical selling situations, and secondly both of the theoretical grounds-Adaptation Theory, and Game Theory - will be taken into consideration as a whole while the cases are analyzed.

\subsection{Case One}

\subsubsection{The Case}

A customer is looking at a display of Cross gold pens and pencils. Here is the conversation between the customer and the shop keeper.

Customer: I'm looking for a graduation gift for my brother, but I'm not necessarily looking for a pen and pencil set.

Salesperson: Is your brother graduating from college or high school?

Customer: He is graduating from college this spring. 
Salesperson: I can show you quite a few items that would be appropriate gifts. Let's start by taking a look at this elegant Cross pen and pencil set. Don't they look impressive?

Customer: They look too expensive. Besides, a pen and pencil set doesn't seem like an appropriate gift for a college graduate.

Salesperson: You're right, a Cross pen and pencil set does look expensive. Just imagine how impressed your brother will be when he opens your gift package and finds these beautiful writing instruments. Even though Cross pen and pencil sets look expensive, they are actually quite reasonably priced, considering the total value you are getting.

Customer: How much does this set cost?

Salesperson: You can buy a Cross pen and pencil set for anywhere from $\$ 15$ to $\$ 300$. The one I am showing you is gold-plated and costs only $\$ 28$. For this modest amount you can purchase a gift for your brother that will be attractive, useful, last a lifetime, and will show him that you truly think he is deserving of the very best. Don't you think that is what a graduation gift should be?

Customer: You make it sound pretty good, but frankly I hadn't intended to spend that much money.

Salesperson: Naturally, I can show you something else. However, before I do that, pick up this Cross pen and write your name on this pad of paper. Notice that in addition to good looks, Cross pens offer good writing. Cross is widely acclaimed as one of the best ball-point pens on the market. It is nicely balanced, has a point that allows the ink to flow on the paper smoothly, and rides over the paper with ease.

Customer: You're right, the pen writes really well.

Salesperson: Each time your brother writes with this pen, he will remember that you gave him this fine writing instrument for graduation. In addition, Cross offers prestige. Many customers tell us that Cross is one of the few pens they have used that is so outstanding that people often comment on it by brand name. Your brother will enjoy having others notice the pen he uses is high in quality.

Customer: You're right. I do tend to notice when someone is using a Cross pen.

Salesperson: You can't go wrong with a Cross pen and pencil set for a gift. Shall I wrap it for you?

Customer: It's a hard decision.

Salesperson: Your brother will be very happy with this gift.

Customer: Okay. Go ahead and wrap it for me. (Hafer, 1993, pp. 88-89)

\subsubsection{The Analysis}

In this case, at the beginning of the whole selling process, the salesperson identifies the customer's need-looking for a graduation gift for her brother-by asking a question, a technique commonly used by salespeople in discovering customers' underlying needs, and then makes a recommendation - a Cross pen and pencil set, which he thinks will meet the customer's need. However, the customer raises an objection concerning the appropriateness of the recommended gift. Then the salesperson deals with the objection by firstly admitting the high price of the product, an adaptation to the customer's psychological desire for sympathy, and then asking the customer to imagine how happy her brother will be when he receives this beautiful gift, an adaptation to the customer's desire for compliment. In the process of selling presentation, when the customer says that the price of the product exceeds her budget, a price objection, the salesperson copes with it by pointing out the features of the recommended product and then associates these features with the benefits that the customer will get: her brother will get prestige by owning such an outstanding pen since his friends will compliment it for its high quality every time he uses it, and then the customer herself will be happy because her desire to make her brother happy is satisfied. Here, the salesperson uses benefit method of persuasion to adapt to the customer's desire for compliment. Finally the salesperson employs the assumptive-close method of persuasion (assuming the prospect will buy and the only thing left is to wrap it for her) in his attempt to close the deal. Although, at this final stage he meets with another objection from the customer-her uncertainty about her decision, the salesperson succeeds in persuading her to buy through mentioning the possible satisfaction the receiver will get.

In this selling game, one party, the salesperson uses such persuasive strategies as question technique of needs discovering, compliment method of presentation and assumptive-close method to adapt to such communicative environments as psychological desire for sympathy and that for compliment. Although, during the process some objections (to the high price, to the appropriateness of the product as a gift and of the uncertainty of the buying decision) are raised by the customer, the other party in the game, who tries to minimize her losses and maximize 
her gains through this way, the salesperson successfully gains the customer's cooperation and finally wins because he achieves his goal of getting economic benefits by selling his product. At the same time, the customer also wins because by buying this product she gets a wonderful gift for her brother, and that will make his brother happy, which will in turn makes her satisfied. In this sense, a bilateral optimalization or a win-win situation is realized in this selling game.

\subsection{Case Two}

\subsubsection{The Case}

Ann Saroyan is a salesperson for the Electronic Office Security Corporation. She sells industrial security systems that detect intruders and activate an alarm. On her first visit to a large accounting firm, she asked the receptionist who she should see and was referred to Joe Bell. After she waited 20 minutes, Bell asked her to come into his office. The conversation went like this:

Salesperson: This is a beautiful old building, Mr. Bell. Have you been here long?

Buyer: About 10 years. Before we moved here, we were in one of those ugly glass and concrete towers. Now, you wanted to talk to me about office security.

Salesperson: Yes, Mr. Bell. Tell me, do you have a burglar alarm system at present?

Buyer: No, we don't. We've never had a break-in here.

Salesperson: I see. Could you tell me what's the most valuable item in your building?

Buyer: Probably the computer.

Salesperson: And is it fairly small?

Buyer: Yea, amazingly, it's not much bigger than a typewriter.

Salesperson: Would it be difficult to run your business without it—if it were stolen for example?

Buyer: Oh, yes, that would be quite awkward.

Salesperson: Could you tell me a bit more about the problem you would face without your computer?

Buyer: It would be inconvenient in the short term for our accounts and records people, but I suppose we could manage until our insurance gave us a replacement.

Salesperson: But without a computer, wouldn't your billing to customers suffer?

Buyer: Not if we got the replacement quickly.

Salesperson: You said the computer itself is insured. Do you happen to know if the software- - the programs, your customer files - are also insured?

Buyer: I don't believe so; our insurance covers the equipment only.

Salesperson: And do you keep backup records somewhere else-in the bank, for example?

Buyer: No, we don't.

Salesperson: Mr. Bell, in my experience, software isn't left behind after a theft. Wouldn't it be a serious problem to you if that software were taken?

Buyer: Yes, you're right, I suppose. Redevelopment would certainly cost a lot. The original programs were expensive.

Salesperson: And even worse, because software development can take a long time, wouldn't that hold up your billings to customers?

Buyer: We could always do that manually.

Salesperson: What effect would that have on your processing costs?

Buyer: I see your point. It would certainly be expensive to run a manual system, as well as being inconvenient.

Salesperson: And if you lost your software, wouldn't it also make it harder to process customer orders?

Buyer: Yes. I don't have much contact with that part of the business, but without order processing and stock control I'm sure we would grind to a halt in a matter of days.

Salesperson: Are there any other items in the building that would be hard to replace if stolen?

Buyer: Some of the furnishings. I would hate to lose this antique clock, for example. In fact, most of our 
furnishings would be very hard to replace in the same style.

Salesperson: So, if you lost them, wouldn't it hurt the character of your office?

Buyer: Yes, it would be damaging. We've built a gracious, civilized image here, and without it we would be like dozens of other people in our business - the glass and concrete image.

Salesperson: This may sound like an odd question, but how many doors do you have at ground level?

Buyer: Let me see... uh... six.

Salesperson: About 10 or a dozen.

Salesperson: So there are 16 or 18 points where a thief could break in, compared with 1 or 2 points in the average glass and concrete office. Doesn't that concern you?

Buyer: Put that way, it does. I suppose we're not very secure.

After a detailed discussion about the features and advantages of the security system that can be offered by his company, the salesperson successfully signed a contract with the customer and ended the deal. (Zhao \& Su, 2007, pp. 77-78)

\subsubsection{The Analysis}

This is another successful case of personal selling. At the initial stage, the salesperson, who works for a security company, approaches the potential buyer by complimenting the building in which the office of the latter is located. Here the compliment method is used, which is a commonly used persuasion technique, and at the same time both an adaptation to the physical world, more specifically, to the selling environment, and an adaptation to the customer's mental world, and particularly the desire for compliment, are made. In the following stage, the conversation continues with many questions raised by the salesperson and answers made by the prospect. Given the nature of these questions - specified questions deliberately raised one by one based on the customer's previous answers, hence logical ones - the general persuasion strategy adopted is that by means of logos in Aristotle's term, and more specifically the multiple-question method is used according to theories concerning personal selling. During this selling stage, several objections are presented by the prospect, which are indicated by such statements as "We've never had a break-in here", "but I suppose we could manage until our insurance gave us a replacement", and "We could always do that manually". These objections show the prospect's reluctance to totally agree with what the salesperson said with an aim to avoid being forced to make a deal. However, the salesperson succeeds in inducing the customer to agree with her step by step and finally makes the customer admit the insecurity of the office building, and thus a need is generated in the customer's mind. Here an adaptation to the customer's mental world, particularly the need for security is made by the salesperson. Although, the prospect does not initially feel a need for her product, through the use of some persuasion strategies or techniques and the adaptation to the physical world as well as the mental world the salesperson successfully convinces the prospect of a need for a security system.

In this selling game, one party, the salesperson uses such persuasive techniques as compliment method and multiple-question method to adapt to both the physical and the mental world. However, the other party, the prospect, does not passively agree with the salesperson, and raises some objections in an attempt to minimize his losses and thus maximize his gains. In the final stage of this communication game, the salesperson closes the selling process successfully with cooperation and decision to buy her service, therefore achieving her goal of gaining economic benefits by selling her service, and meanwhile, the customer satisfies his own need for avoidance of economic losses caused by insecurity by buying the service. As a result, a bilateral optimalization is realized in this selling game.

\subsection{Case Three}

\subsubsection{The Case}

A university student enters a bicycle store. And after a brief greeting, the dialog between him and the store owner goes like this:

Salesperson: This Murphy ten-speed bicycle should handle your need to commute to and from work at the university each day.

Prospect: Well, it sounds like it.

Salesperson: What do you think of this bike?

Prospect: It seems okay. 
Salesperson: What color would you like?

Prospect: I think yellow is a nice color.

Salesperson: Well, let's go over to the cash register and you can ride home.

Prospect: I'm not sure.

Salesperson: Well, this bike is on sale only until tomorrow, after which the price goes up by fifteen dollars, so I would advise buying now.

Prospect: Well, it seems like a nice bike, but it's a little expensive.

Salesperson: That's right and that's why you should buy it. You get what you pay for.

Prospect: I suppose.

Salesperson: I tell you what. Let's look at this systematically. Let's draw a $\mathrm{T}$ on this sheet of paper and write down some reasons for buying on one side of it, and some reasons for not buying this Murphy on the other side.... Now doesn't it sound like you should buy?

Prospect: I don't know. I think I'm going to think it over. I'll be back in touch with you later. (Exits store) (Zhao \& Su, 2007, pp. 56-57)

\subsubsection{The Analysis}

This is a failed case of personal selling, which happens in a retail store. As a start, the salesperson approaches the prospect by stating the benefit the latter can get from his product. Here the product-benefit technique is used and an adaptation to the customer's mental desire for benefit-seeking is made. From the prospect's tone in his response, one can judge he is not so satisfied with this type of bicycle recommended by the salesperson. But the salesperson seems to fail to realize this and tries to use the recommendation technique attempting to close the deal, which is indicated in this statement "let's go over to the cash register and you can ride home", which is also a failure to adapt to the conversational context. Confronted with the prospect's objection- "I'm not sure", the salesperson uses urgency technique in an attempt to push the prospect to buy, which is also an adaptation to the physical world, and particularly to the stretches of time - "this bike is on sale only until tomorrow, after which the price goes up by fifteen dollars". Then the prospect raises a price objection: "it's a little expensive". However, instead of justifying the price by introducing features and advantages of this bike and then generating benefits in the prospect's mind, the salesperson tries vainly to say that the price is reasonable without giving any specific reasons, a failure to adapt to the prospect's mental world. At the final stage, the salesperson adopts the technique of listing cons and pros, a popular close technique in personal selling in an aim to convince the prospect to buy, but he fails. The reason lies in his inability to adapt to the particular selling situation, since at previous stages he did not present any unique features and benefits of his product and the prospect gets the impression that the product is just ok and it is expensive, an indication of the salesperson's inability to adapt to the prospect's mental desire for benefit-seeking. As a result, he is left with no reasons for buying and all reasons for not buying.

The salesperson as one party in this selling game uses such persuasion strategies as the product-benefit technique, the urgency technique and that of listing cons and pros as adaptation to such communicative contexts as the physical world and mental world to achieve his economic goal of earning money by selling his product. And the prospect, the other party, responses with his not-so-satisfied tone and a price objection to minimize his economic losses of buying a dissatisfied product at a high price. The final result is that the prospect does not buy the product and thus no win-win situation is realized, due to the salesperson's failure to adapt to the conversational context and the customer's mental desire for benefit-seeking as well as his misuse of close technique.

\subsection{Case Four}

\subsubsection{The Case}

Angela Defore is a salesperson at Comcast, the company with the cable TV rights for the city of Beloit and its surrounding suburbs. After Defore graduated from Wayne State University with a BA in history, she went to work for the city in the community services department. When the economy slowed down, she was laid off and went to work for Comcast, where she has been working in sales for two years. Defore is married, has two children, and is an active volunteer in programs for homeless persons.

Defore is making her first call on Steve Sinor, the new director of advertising at Beloit National Bank. As Defore enters Sinor's office, she notices several graphs on the wall indicating the number of new accounts opened, total deposits, and market share over time. A plaque signifying Sinor's selection as Southwestern Advertising Executive of the Year is prominently displayed. 
Defore [extends her hand warmly and then takes a seat]: Good morning, Mr. Sinor. This is really a beautiful day. How are you?

Sinor [hesitates at first and then extends his hand]: I have just a few minutes to talk with you. My schedule is really tight today. Now tell me what you have to offer [sits down without demonstrating an emotional response].

Defore: let me take a second to tell you why I made an appointment to see you. I was talking with Joan Waters at Fidelity Mutual Life Insurance. She said she met you at a recent Southwestern Advertising Executives luncheon. She has been using Comcast in her media plan and mentioned that you might be interested in advertising on cable TV.

Sinor: I really can’t remember Ms. Waters. You meet so many people at these luncheons.

Defore: She really is an interesting person. We worked together as volunteers in the Homeless in America program last fall. Are you involved in many community activities?

Sinor: Not really [looks at watch].

Defore: Well, Ms. Waters told me that you were developing a new advertising campaign for the bank. I hear the campaign will stress customer service. I really think that is a great idea. Banks should be more concerned about providing good service.

Sinor: We did a lot of market research to develop this new campaign. Our research shows that customer service is particularly important to people in the eastern suburbs. We hope to increase our share of new deposits by 3 percent over the next six months. Tell me something about what you can do for us.

Defore: I think we are the ideal media for your new campaign. Fidelity Mutual has been very pleased with the response to its commercials for homeowner insurance policies.

Sinor: that's interesting. What is its target market?

Defore: Fidelity has been targeting its campaign toward lower-income families in the western suburbs. Homeowner policy sales doubled six months after Fidelity placed the first ads on cable TV.

Sinor: Doubled?

Defore: At least doubled, I think.

Sinor: Could you be more specific about your reach in the eastern suburbs? How many families subscribe to your cable TV service? How often do they watch the cable channels?

Defore: I don't have the specific information with me, but I know that our coverage is very good. More and more people are watching cable channels. You know...

Sinor: Excuse me, but I have to go to another meeting. When you get some more specific information, you can leave it with my assistant. (Futrell, 2004, pp. 42-45)

\subsubsection{The Analysis}

In this case, the salesperson named Angela Defore, in his first call to the customer called Steve Sinor, starts the conversation by greeting and talking about the weather, which is a frequently used way by salespeople in the initial stage of selling. However, from the prospect's response, both verbally ("My schedule is really tight") and non-verbally (hesitates at first; without no emotional response), we can see that he is reluctant to receive the salesperson. Then the salesperson states the reason for this call and strategically mentions that the woman called Joan Waters with whom she thought the prospect might know well has recommended her to have this visit, also a usual persuasive way, referred to as referral approach, for salespeople in their attempts to build rapport and close the distance with customers. However, to her disappointment, the prospect claims that he cannot recognize this woman, which apparently is an indication that this method does not work. He then continues to talk about the woman as well as their experience as volunteers, through which he hopes he can dig out the prospect's own experience. But unfortunately, the latter replies that he did not take part in similar activities. Sensing the indifference in the prospect's tone, the salesperson quickly turns the topic of the conversation to the new advertising campaign which the prospect intends to carry out, thus successfully arousing his interest in carrying on the conversation. Here benefit method of persuasion is used in the process of selling presentation. At this stage, it seems that the conversation goes very well, since the salesperson's presentation is to the point. However, at the final stage of the communication, the salesperson fails to obtain commitment from the prospect, because she lacks some specific information ready before hand and thus leaves an impression that her former remarks are not so trustworthy. 
Actually, Defore is a qualified salesperson in terms of the persuasive language strategies she uses in approaching the customer and arousing the customer's attention. But her failure lies in that she does not get well prepared for the call. This case also shows an adaptation to physical environment in that the salesperson, while entering the prospect's office, notices several graphs on the wall indicating the number of new accounts opened, total deposits, and market share over time. This is the reason why she uses the recommendation of an acquaintance of the prospect as the reason for her visit. And the adaptation to the psychological desire for rapport building and that to the need for benefit seeking also occur when the salesperson uses the referral approach and changes the conversational topic to attract the latter's interest respectively. Also, in this selling game, the prospect frequently shows his indifference to the salesperson, which is an indication that he is trying to minimize his loss, both in terms of time and economical benefits. He clearly knows that the salesperson's goal is to achieve economical benefits by persuading him to buy the salesperson's service, so he has to prevent himself from being pushed into making any rush decision. Meantime, he knows that maybe he can actually gain from the salesperson's service if it can really satisfy his needs, and hence he still gives chances for the conversation to continue until the time when the salesperson is unable to offer specific information. The reason for him to end the conversation is that he does not want to take risks, for the salesperson's trustworthiness is challenged. As a result, the game goes to a dead end, since no bilateral optimization is achieved.

\subsection{Summary}

In this section four typical complete selling cases are analyzed according to the theoretical framework of this study. Two of them are successful ones in the sense that the salesperson gains the deal by using appropriate persuasion techniques to adapt to the communicative context. The other two are failed ones since the salesperson fails to gain the deal as a result of his misuse of certain persuasion techniques and thus his inability to adapt to the conversational situation. From these examples, we can safely say that the proper use of persuasion strategies and the adaptation to the communicative context are essential for a salesperson to succeed in selling.

\section{Conclusion}

In this study cases of face-to-face persuasive personal selling have been analyzed, according to Verschueren's Linguistic Adaptation Theory and Game Theory. The sellers' choice of language and strategies is motivated by adaptation to one of the three worlds: the physical, social and mental world. Thus we discover the underlying factors which can explain why salespeople speak in a particular way by fully taking into account the context in which the conversation happens. Meanwhile, the whole process of personal selling can be viewed as an interactive game, in which customers also play an important role in the selling result. Whether a win-win situation can be achieved in this game depends on both the salesperson's choice of strategies to adapt to the particular communicative context and the degree of the customer's cooperation.

However, the present study suffers from several limitations. In terms of methodology, the research data is collected from books and thus may be challenged in its reliability and validity. Actual live selling cases could be collected by the author through audio or video recording in the future to better the research methodology. Another limitation lies in the fact that the present study only reveals a small portion of the complete picture of the theories concerning adaptation and game due to the author's limited knowledge. These theories have much more complicated interpretation and much more widespread applications, which are worth further exploring and researching.

\section{Acknowledgments}

My acknowledgements are particularly extended to Mr. Chen Linhan, my supervisor, who has inspired me with her expertise on which this research paper is based and constructed. Likewise, I want to express my sincere gratitude to all my colleagues in International College of Guangdong University of Foreign Studies for their help and support during the period when the research was conducted. I would also like to express my heartfelt thanks to my family, especially my husband who has not only given me encouragement but also helped to take care of our baby when I was fully engaged in the research work.

\section{References}

Anderson, R. (1995). Essentials of personal selling: The new professionalism. Englewood Cliffs, NJ: Prentice-Hall.

Aristotle. (1991). On rhetoric (G. A. Kennedy, Trans.). Oxford, England: Oxford University Press.

Carlson, L. (1983). Dialogue games: An approach to discourse analysis. Boston: D. Reidel Publishing Company.

Davis, M. D. (2017). Game theory: A nontechnical introduction. Beijing: China Renmin University Press. 
Fisher, W. R. (1987). Human communication as narration: Toward a philosophy of reason, value, and action. Columbia: University of South Carolina Press.

Futrell, M. C. (2004). Fundamentals of selling. Irwin McGraw-Hill.

Hafer, C. J. (1993). The professional selling process. West Publishing Company.

Hintikka, J. (2006). Game theoretical semantics. Encyclopedia of Language and linguistics, 40(1), 721-724. https://doi.org/10.1016/B0-08-044854-2/01000-2

Larson, C. U. (2004). Persuasion: reception and responsibility. Beijing: Peking University Press.

Neumann, J. V., \& Morgenstein, O. (2004). Theory of games and economic behavior. Beijing: Joint Publishing Company.

Seliger, W. H., \& Shohamy, E. (1989). Second language research methods. London: Oxford University Press.

Sun, L. H. (2007). Learning to sell by watching movies. Beijing: China Renmin University Press.

Timothy, A. B. (2002). Persuasion in the media age. Boston: McGraw-Hill Companies, Inc.

Verschueren, J. (1999). Understanding pragmatics, Beijing: Foreign Language Teaching and Research Press.

Weitz, B. A., Castleberry, S. B., \& Tanner, J. F. (2004). Selling: Building partnerships. McGraw-Hill/Irwin.

Weymes, P. (1990). How to perfect your selling skills. London: Kogan Page Ltd.

Zhao, H. G. \& Su, C. L. (2007). Selling by appropriately using left and right brains. Beijing: People's Post and Telecommunications Publishing House.

\section{Copyrights}

Copyright for this article is retained by the author(s), with first publication rights granted to the journal.

This is an open-access article distributed under the terms and conditions of the Creative Commons Attribution license (http://creativecommons.org/licenses/by/4.0/). 